\title{
Chemical oxygen diffusion coefficient measurement by conductivity relaxation - correlation between tracer diffusion coefficient and chemical diffusion coefficient
}

\author{
Mauvy F., Bassat J. M., Boehm E., Dordor J. P., Grenier J. C., Loup J. P.
}

\begin{abstract}
Chemical oxygen diffusion coefficient $(\bar{D})$ was measured by conductivity relaxation experiments on $\mathrm{La}_{2} \mathrm{Cu}_{0.5} \mathrm{Ni}_{0.5} \mathrm{O}_{4+\delta}$ ceramics. This method consists of abruptly changing the oxygen partial pressure in the surrounding atmosphere of the sample. The consequent evolution of the electrical conductivity is recorded as a function of time, at fixed temperature. The transient behaviour during the re-equilibration process is analysed on the basis of the second Fick's law. In parallel, the oxygen tracer self-diffusion coefficient $\left(D^{*}\right)$ was derived from isotopic exchange experiments monitored by SIMS analysis. Finally, the oxygen over-stoichiometry $(\delta)$ was computed from thermogravimetric experiments, under different $\mathrm{pO}_{2}$, in order to determined the thermodynamic factor (y). A quantitative agreement between $\bar{D}$ and $y \times D^{*}$, observed over a wide temperature range $\left(500-900^{\circ} \mathrm{C}\right)$, confirms the validity of the experimental method and of the Wagner's theory, applied to the oxygen diffusion in this compound.
\end{abstract}

\section{INTRODUCTION}

The decrease of the working temperature of the Solid Oxide Fuel Cells (SOFC), down to $700^{\circ} \mathrm{C}$, lowers the rate of the oxygen reduction. Consequently, the ionic conduction and the surface exchange reaction must be improved to keep the yield as high as possible. Assuming the cathode to be a pure electronic conductor, the surface reaction can only take place at the triple phase boundary (TPB). Using a mixed conductor as a cathode transforms the TPB into a double interface and increases the reaction area. Nevertheless, in this case direct oxygen ionic conduction measurements are difficult due to the low value of the ionic transport number of the studied compound. An alternative way to determine the ionic conduction is to measure the oxygen diffusion. Theoretically, the ionic conduction can be deduced from the Nernst-Einstein relation:

$$
\sigma O=\frac{Z_{o}^{2} F^{2} D_{o}^{*} C o}{R T}
$$

where $\mathrm{z}_{O} \mathrm{~F}$ represents the electrical charge of an oxygen mole. $\mathrm{D}_{O} *$ and $\mathrm{C}_{O}$ are the tracer self-diffusion coefficient and the concentration of oxide ions, respectively. The chemical diffusion coefficient $\bar{D}_{O}$ can be calculated according to the relation: [1] $\bar{D} \approx \gamma \times \mathrm{D}_{O}^{*}$ in which y represents a thermodynamic factor : $\gamma=\frac{1}{R T} \mathrm{x} \frac{\partial\left(\mu_{O 2}\right.}{\partial \operatorname{InC} C_{O}}=\frac{1}{2} \mathrm{x}$ $\frac{\partial \operatorname{InpO} O_{2}}{\partial \operatorname{In} C_{O}}$ where $\mu\left(\mathrm{O}_{2}\right)$ is the oxygen chemical potential, $\mathrm{p}_{O 2}$ the oxygen partial pressure. From an experimental point of view, the thermodynamic factor $\gamma$ can be obtained by thermogravimetric analysis (TGA) and $\bar{D}_{O}$ electrical conductivity relaxation, for example.[1 and 2] In this study, we have measured the oxygen chemical diffusion coefficient $\bar{D}_{O}$ of the mixed conductor oxide $\mathrm{La}_{2} \mathrm{Cu}_{0.5} \mathrm{Ni}_{0.5} \mathrm{O}_{4+\delta}$ by conductivity relaxation, and the thermodynamic factor $\gamma$ by TGA. Furthermore, we have checked the validity of relation (2) by measuring the tracer self-diffusion coefficient $\mathrm{D}_{O}^{*}$ using an isotopic oxygen ${ }^{16} \mathrm{O} /{ }^{18} \mathrm{O}$ exchange.[3]

\section{EXPERIMENTAL}

\subsection{Sample preparation}

The samples have been prepared using the nitrate-citrate method: a stoichiometric mixture of $\mathrm{La}_{2} \mathrm{O}_{3}$ (Merck, $\geqslant 99 \%$ ), $\mathrm{NiO}$ (Aldrich, 99.9\%) and $\mathrm{CuO}$ (Merck, $\geqslant 99 \%$ was dissolved in nitric acid. Then citric acid (Aldrich, 99.99\%) was added. After firing in a sand bath, the self-combustion of the precipitate gave powdered precursors exhibiting a high chemical reactivity. Several annealings at $T=1000^{\circ} \mathrm{C}$, separated by grinding steps, were necessary to obtain a pure phase. After sintering, the density of the pellet is $95 \%$ and the grain size about $2-4$ $\mu \mathrm{m}$. 


\subsection{Electrical conductivity relaxation}

The basis of the chemical relaxation experiments consists in abruptly changing the oxygen chemical potential (obtained by modification of $\mathrm{p}_{\mathrm{O} 2}$ of the surrounding atmosphere) and in recording the sample conductivity vs time until an equilibrium is reached.[4 and 5] During the oxidation step, the oxygen is incorporated into the material, whereas during the reduction step, oxygen is released from the structure. The transient behavior in the re-equilibration process can be described by the second Fick's law. [5] If the chemical diffusion can be assumed to be the rate determining step, the second Fick's law leads to the following equation determined by Crank, under appropriate boundary conditions: [2 and 6]

$$
\frac{M t}{M \infty}=1-\sum_{\square-0}^{\infty} \frac{8}{(2 n+1)^{2} \pi^{2}} \times \exp \left[-\frac{(2 n+1)^{2} \pi^{2} \tilde{D} t}{4 L^{2}}\right]
$$

where $\mathrm{L}$ is the diffusion length (half of the sample thickness) and $\mathrm{t}$ the time. $\mathrm{Mt} / \mathrm{M} \infty$ represents the ratio of the total mass of diffused oxide ions at time t, over the value obtained for an infinite time. Assuming constant the number of charges and their mobility, the conductivity ratio of the sample is directly related to the mass ratio:

$\frac{M t}{M \infty}=\frac{\sigma_{a p p}(t)-\sigma_{a p p}(0)}{\sigma_{a p p}(\infty)-\sigma_{a p p}(0)}$

In this formula $\sigma(0)$ and $\sigma(\infty)$ stand stand for the apparent conductivity at $\mathrm{T}=0$ (initial), at time $\mathrm{t}$ (during the relaxation) and $\mathrm{t} \rightarrow \infty$ after reaching a new equilibrium state). Least-square fitting of the relaxation data in (4) and (5) allows us to determine the chemical diffusion coefficient $\tilde{D} o$.

Electrical conductivity relaxation experiments were performed using the four probe method. Various atmospheres surrounding the sample were obtained by flowing a mixture of oxygen and nitrogen into the sample chamber using two mass flow controllers. Oxygen partial pressure used for conductivity relaxation measurements were 0.01 and $0.21 \mathrm{~atm}$.

The time necessary to replace the atmosphere inside the cell and to obtain a stable $\mathrm{p}_{\mathrm{O} 2}$ is short compared with the relaxation time $(\sim 30 \mathrm{~s})$. Electrical conductivity was measured during the re-equilibration process. A typical example of the conductivity behaviour of $\mathrm{La}_{2} \mathrm{Cu}_{0.5} \mathrm{Ni}_{0.5} \mathrm{O}_{4+\delta}$ is shown in Fig. 1. Reversible conduction properties were observed for oxidation as well as reduction steps. However, the reduction stage was not exploited as the time to shift $\mathrm{p}_{\mathrm{O} 2} \mathrm{rom} 0.21$ to $0.01 \mathrm{~atm}$ is much longer than the reverse step (for technological reasons). The conductivity response was then plotted as a function of $1-((\sigma(t)-\sigma(0)) /(\sigma(\infty)-\sigma(0)))$. Fractional conductivity changes were fitted with respect to $(4)$ and (5) to determine the oxygen chemical diffusion $\tilde{D}$.

Experimental and fitted data are shown in Fig. 2.

\subsection{Isotopic exchange measurements}

The oxygen tracer self-diffusion coefficient $\left(\mathrm{D}^{*}\right)$ and the surface exchange coefficient $(\mathrm{k})$ were determined by ${ }^{18} \mathrm{O}$ tracer exchange method (using the IEDP process).[7]

First of all, the samples were annealed so that the composition is equilibrated at the same $\mathrm{p}_{O 2}$ and temperature $\left(T=500,600,700,800\right.$ and $\left.900{ }^{\circ} \mathrm{C}\right)$ as for further ${ }^{18} \mathrm{O}$ exchange annealing. In a second step, the samples were annealed in a closed chamber but containing isotopically enriched gas for a given time. After quenching the samples, the cell was again evacuated, and isotopically enriched oxygen $\left({ }^{18} \mathrm{O}\right.$, CEA, Euriso-top $\left.97 \%\right)$ was introduced with the same $\mathrm{p}_{\mathrm{O} 2}\left(\mathrm{P}=0.21 \mathrm{~atm}\right.$ and $\left.\mathrm{p}_{\mathrm{O} 2}=1 \mathrm{~atm}\right)$ as previously. In the third step, the ${ }^{18} \mathrm{O}$ penetration profile inside the sample was determined, using a Secondary Ion Mass Spectroscopy (SIMS).

Prior to the SIMS analysis, all the pellets were cut across the diameter. The SIMS instrument used was a CAMECA IMS ion microprobe, equipped with a mass analyzer. The recorded profiles were used to determined $\mathrm{D}^{*}$ and $\mathrm{k}$, by a non-linear least squares regression, based upon the Crank's model. Main results are summarized in Table 1.

The oxygen ionic conductivity $\sigma_{O}$ deduce from $\mathrm{D}^{*}$ according to Nernst-Einstein equation $\left(\sigma O=\frac{4 . e_{2} C o}{k T} \times \mathrm{D}^{*}\right)$ have been calculated and is also reported in Table 1 . The oxygen concentration $\left(\mathrm{C}_{O}\right)$ was calculated using $\mathrm{C}_{O}=(4+\delta) / \mathrm{V}_{m}\left(\mathrm{~V}_{m}\right.$ being the unit cell volume).[8] As the ionic conductivity is three or four orders of magnitude smaller than the electronic conductivity, [9] we deduced that the electronic transference number is close to 1.

In order to compare $\mathrm{D}^{*}$ (from SIMS profiles) and $\tilde{D}$ o (from conductivity relaxation), the thermodynamic factor $\gamma$ was determined using thermogravimetric experiments (TGA) according to (2) and (3). 


\subsection{Thermogravimetric analysis}

After an initial equilibration step, the sample was successively heated up to the same temperatures as for isotopic exchange measurements $\left(T=500,600,700,800,900{ }^{\circ} \mathrm{C}\right)$. The equilibration step lasts until the weight is stabilized $( \pm 5 \mu \mathrm{g})$. Once this condition was fulfilled, under air $\left(\mathrm{p}_{\mathrm{O} 2}=0.21 \mathrm{~atm}\right)$, the oxygen partial pressure was decreased down to $0.01 \mathrm{~atm}$. After equilibrium, a new working temperature is applied. Finally, the oxide was cooled down to room temperature and the composition was checked to be the expected formulation $\mathrm{La}_{2} \mathrm{Cu}_{0.5} \mathrm{Ni}_{0.5} \mathrm{O}_{4.10}$.

The main TGA results are summarized in Table 2 . The $\gamma$ thermodynamic factor was calculated from $\gamma=1 / 2 \partial \mathrm{ln}$ $\mathrm{p}_{O 2} / \partial \ln \mathrm{C}_{O}$ in which $\mathrm{C}_{O}$ is the oxygen concentration as previously defined $\left(\mathrm{C}_{O}=(4+\delta) / \mathrm{V}_{m}\right)$. [8]

\section{RESULTS AND DISCUSSION IN THE TEMPERATURE RANGE 500-900 ${ }^{\circ} \mathrm{C}$}

In order to examine the surface effects on the diffusion mechanism, conductivity relaxation experiments have been performed on samples of different thicknesses (L). At constant temperature, the relaxation time is affected by the sample thickness provided that the surface exchange is not the limiting process.

Assuming a bulk diffusion, the same diffusion coefficient should be obtained whatever the thickness (at fixed temperature). Fig. 3 shows the Arrhenius plots of the chemical diffusion coefficient measured on two different samples of the same composition $\mathrm{La}_{2} \mathrm{Cu}_{0.5} \mathrm{Ni}_{0.5} \mathrm{O}_{4+\delta}$ but with two different thicknesses. As shown in Fig. 3, Dois insensitive to L. Furthermore, the high value of the surface exchange coefficient $\left(\mathrm{k}=5.10^{-7} \mathrm{~cm} \cdot \mathrm{s}^{-1}\right.$ at $\left.700{ }^{\circ} \mathrm{C}\right)$, measured by isotopic exchange in this oxide, confirms the previous conclusion. Actually, we were unable in this study to extract information about the surface exchange coefficient $(\mathrm{k})$ from the relaxation data. Nevertheless, a more sophisticated model could be used in the future then giving rise to the value of $\mathrm{k}$. [10]

Arrhenius plots of Doand of $\mathrm{D}^{*}$ are reported in Fig. 4. According to these results, it can be pointed out that the value of $\gamma \times \mathrm{D}^{*}$ products and $\tilde{D}$ oare nearly equal, over a wide temperature range $\left(500-900{ }^{\circ} \mathrm{C}\right)$. This observation is in agreement with the Wagner model (Eq. (2)). Furthermore, these results confirm the validity of the electrical relaxation method, applied to mixed conducting oxides. Moreover, oxygen diffusion coefficient and surface exchange coefficient of polycrystalline $\mathrm{La}_{2} \mathrm{Cu}_{0.5} \mathrm{Ni}_{0.5} \mathrm{O}_{4+\delta}$ samples show that these materials seem to be promising materials for SOFC cathodes.

\section{CONCLUSIONS}

The chemical diffusion coefficient $\tilde{D} o$ of $\mathrm{La}_{2} \mathrm{Cu}_{0.5} \mathrm{Ni}_{0.5} \mathrm{O}_{4+\delta}$ was determined by the conductivity relaxation method. The self-diffusion coefficient $\mathrm{D}^{*}$ was measured by isotopic oxygen exchange and the $\gamma$ thermodynamic factor by TGA. Data obtained from these three independent experiments reveal a quantitative agreement between $\tilde{D} o$ and the $\gamma \times \mathrm{D}^{*}$ product. This result agrees with the Wagner model of diffusion. Furthermore, the diffusion coefficient which is an essential feature of the ionic transport, is obtained as easily by electrical relaxation method than the oxygen isotopic exchange method with SIMS analysis.

\section{REFERENCES}

1. J.A. Lane, S.J. Benson, D. Waller and J.A. Kilner, Oxygen transport in $\mathrm{La}_{0.6} \mathrm{Sr}_{0.4} \mathrm{Co}_{0.2} \mathrm{Fe}_{0.8} \mathrm{O}_{3-\delta}$. Solid State Ionics 121 (1999), pp. 201-208.

2. B. Ma, U. Balachandran, J.-H. Park and C.U. Segre, Determination of chemical coefficient of $\mathrm{SrFeCo}_{0.5} \mathrm{Ox}$ by the conductivity relaxation method. Solid State Ionics 83 (1996), pp. 65-71.

3. J. Maier, On the correlation of macroscopic and microscopic rate constants in solid state chemistry. Solid State Ionics 112 (1998), pp. 197-228.

4. J.E. ten Elshof, M.H.R. Lankhorst and H.J.M. Bouwmeester, Chemical diffusion and oxygen exchange of $\mathrm{La}_{0.6} \mathrm{Sr}_{0.4} \mathrm{Co}_{0.2} \mathrm{Fe}_{0.8} \mathrm{O}_{3-\delta}$. Solid State Ionics 99 (1997), pp. 15-22.

5. W. Sitte, E. Bucher, A. Benisik and W. Preis, Oxygen nonstoichiometry and ionic transport properties of $\mathrm{La}_{0.4} \mathrm{Sr}_{0.6} \mathrm{Co}_{0.2} \mathrm{Co}_{3-\delta}$. Spectrochimica Acta A57 (2001), pp. 2071-2076.

6. C. Crank, The Mathematics of Diffusion. (2nd ed.), Clarendon Press, Oxford (1975).

7. J.A. Kilner, B.C.H. Steele and L. Ilkov, Oxygen self-diffusion studies using negative-ion secondary ion mass spectroscopy (SIMS). Solid State Ionics 12 (1984), pp. 89-97. 
8. F. Mauvy, J.M. Bassat, E. Boehm, J.P. Manaud, P. Dordor and J.C. Grenier, Oxygen electrode reaction on $\mathrm{Nd}_{2} \mathrm{NiO}_{4+\delta}$ cathode materials : impedance spectroscopy study. Solid State Ionics 158 (2003), pp. 17-28.

9. Boehm, E., Bassat, J. M., Mauvy, F., Dordor, P., Grenier, J. C. and Pouchard, M., Thermal stability and mixed conductivity in $\mathrm{Ln}_{2} \mathrm{Ni}_{1-x} \mathrm{Cu}_{x} \mathrm{O}_{4+\delta}(\mathrm{Ln}=\mathrm{La}, \mathrm{Pr}, \mathrm{Nd})$ for SOFC cathodes Proc. 4th Eur. Solid Oxide Fuel Cell Forum, ed. A.J. Mc Evoy, Eur. Fuel Cell Forum (2000) pp. 717-724.

10. Boehm, E., Bassat, J. M., Mauvy, F., Dordor, P., Grenier, J. C. and Pouchard, M., Thermal stability and mixed conductivity inLn ${ }_{2} \mathrm{Ni}_{1-x} \mathrm{Cu}_{x} \mathrm{O}_{4+\delta}(\mathrm{Ln}=\mathrm{La}, \mathrm{Pr}, \mathrm{Nd})$ for SOFC cathodes Proc. 4th Eur. Solid Oxide Fuel Cell Forum, ed. A.J. Mc Evoy, Eur. Fuel Cell Forum (2000) pp. 717-724. 
Figure 1. Conductivity relaxation plots for $\mathrm{La}_{2} \mathrm{Cu}_{0.5} \mathrm{Ni}_{0.5} \mathrm{O}_{4+\delta}$ at $700{ }^{\circ} \mathrm{C}$ for oxidation and reduction steps change in pO2 between 0.21 and $0.01 \mathrm{~atm}$.

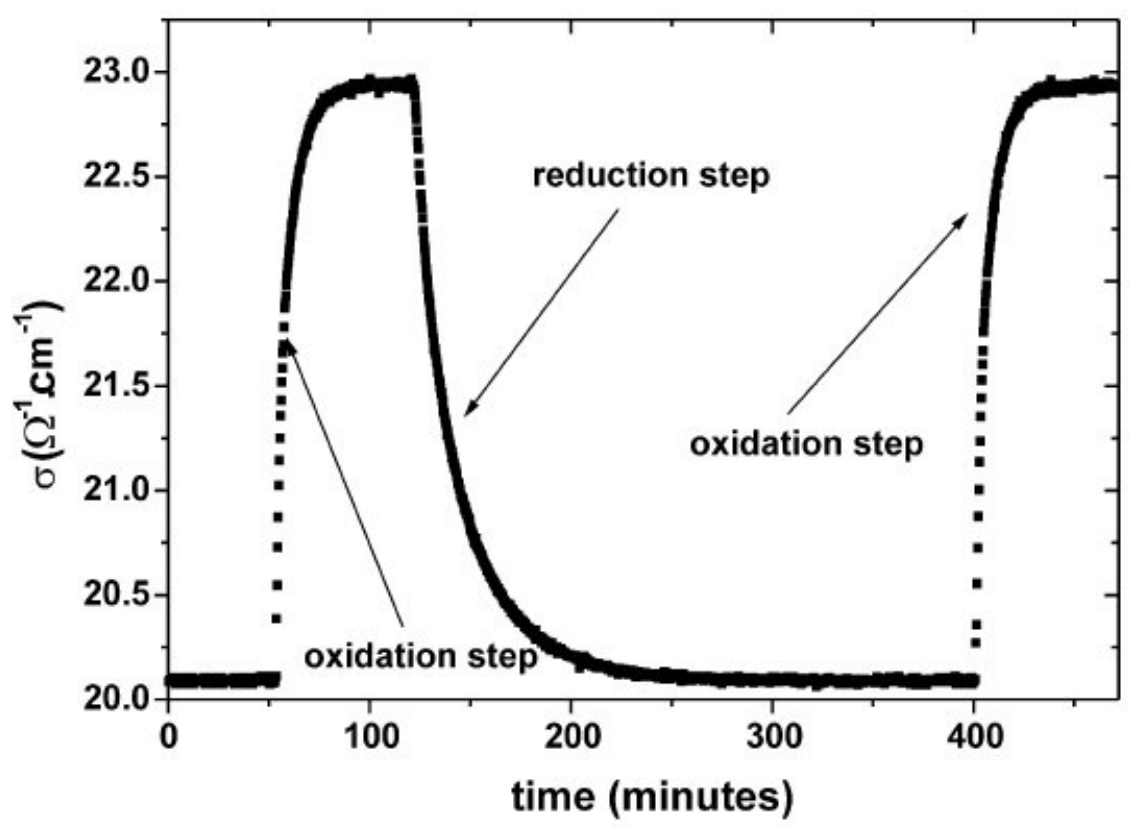

Figure 2. Normalised and fitted conductivity data and fitting curve vs time (at $700{ }^{\circ} \mathrm{C}$ - po2 step from 0.01 to 0.21 atm).

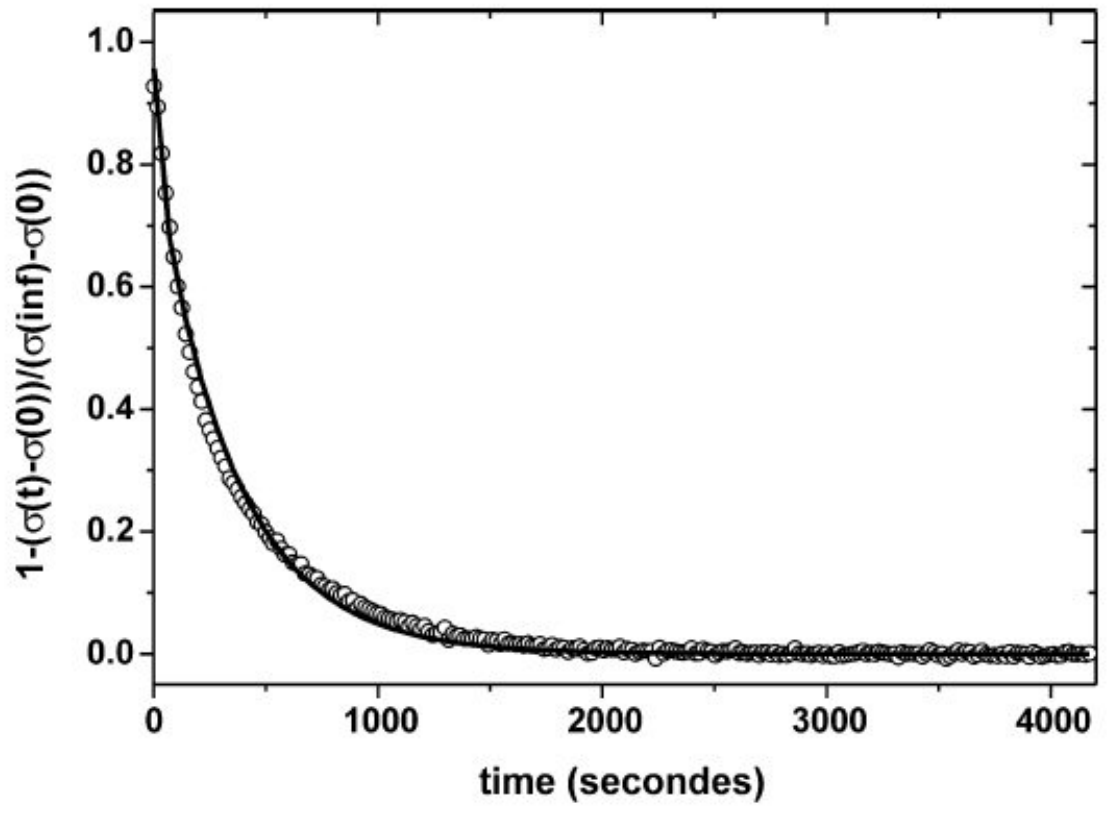


Figure 3. Arrhenius plots of the oxygen chemical diffusion coefficient $(\tilde{D})$ measured on samples with two different diffusion lengths : $\mathrm{L}_{1}=1.3 \mathrm{~mm}(\circ)$ and $\mathrm{L}_{2}=0.7 \mathrm{~mm}(\bullet)$.

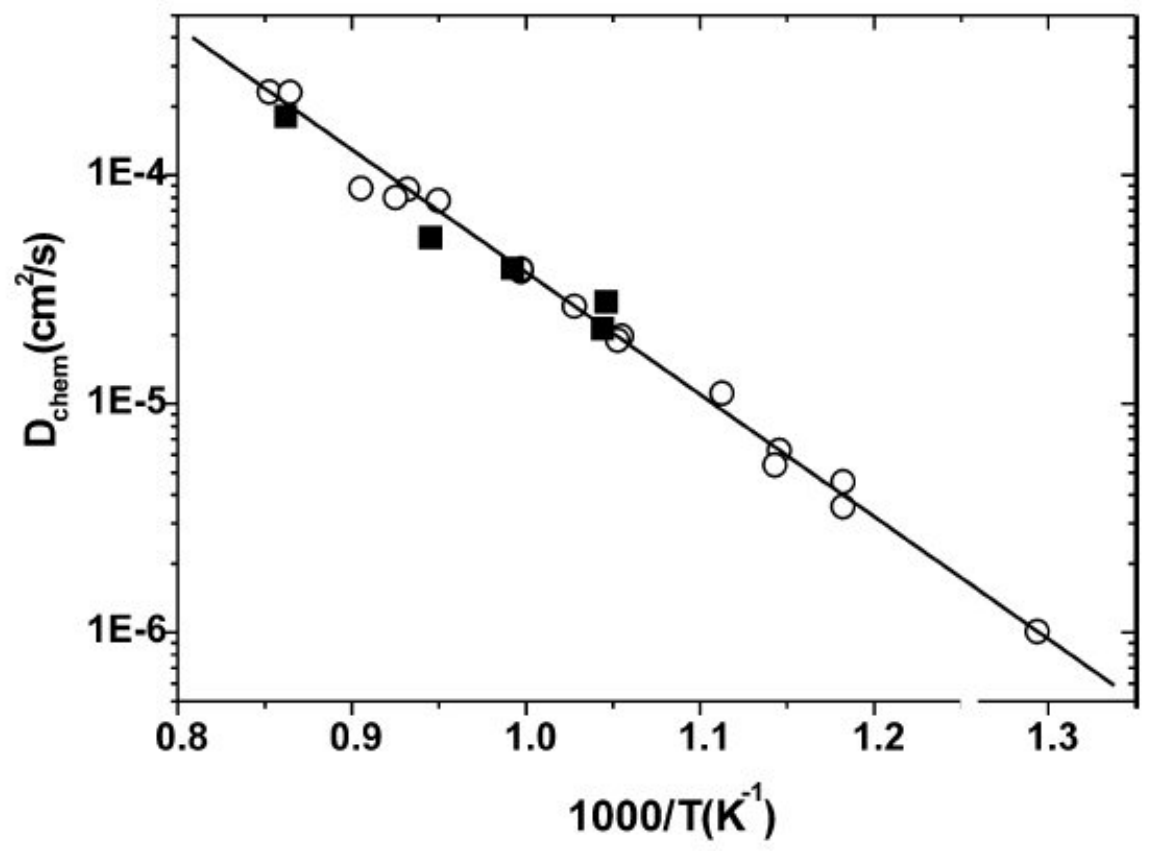

Figure 4. Comparison of the oxygen tracer diffusion coefficient $\mathrm{D}^{*}(\boldsymbol{\square})$, the chemical diffusion coefficient $\tilde{D}(\mathrm{O})$ and the $\gamma \times D *$ product $(\bullet)$ as a function of reciprocal temperature

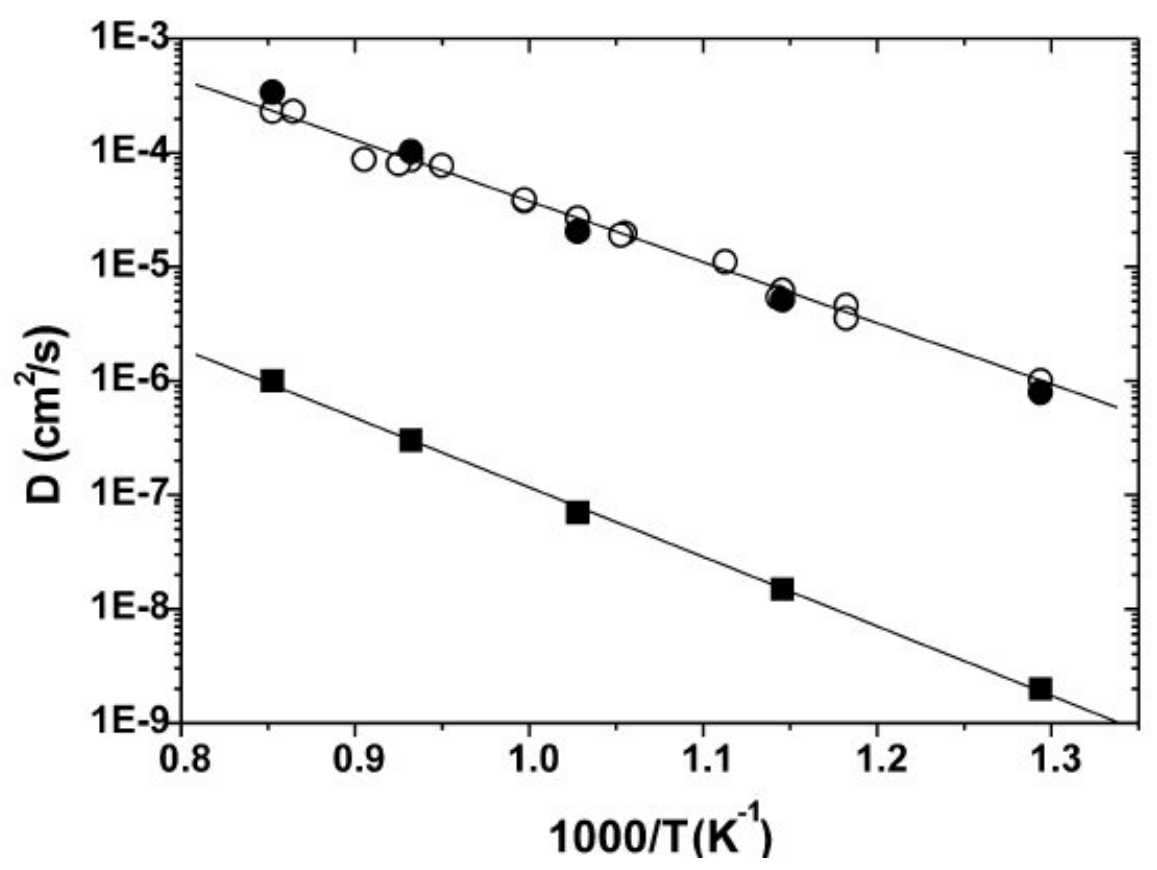


Table 1

Oxygen self diffusion coefficient $\left(\mathrm{D}^{*}\right)$, surface exchange coefficient $(\mathrm{k})$ and oxygen conductivity $\left(\sigma_{\mathrm{O}}\right)$ (deduce from $\mathrm{D}^{*}$ ) and electronic conductivity $\left(\sigma_{e}\right)$ of $\mathrm{La}_{2} \mathrm{Cu}_{0.5} \mathrm{Ni}_{0.5} \mathrm{O}_{4+8}$ as a function of temperature

\begin{tabular}{llllll}
\hline Temperature $\left({ }^{\circ} \mathrm{C}\right)$ & 500 & 600 & 700 & 800 & 900 \\
\hline $\mathrm{D}^{*}(\mathrm{~cm} 2 . \mathrm{s}-1)$ & $2.2 \times 10^{-9}$ & $1.6 \times 10^{-8}$ & $7.5 \times 10^{-8}$ & $3.6 \times 10^{-7}$ & $1.0 \times 10^{-6}$ \\
$\mathrm{k}\left(\mathrm{cm} \cdot \mathrm{s}^{-1}\right)$ & $1.0 \times 10^{-8}$ & $9.8 \times 10^{-8}$ & $5.0 \times 10^{-7}$ & $2.0 \times 10^{-6}$ & $6.2 \times 10^{-6}$ \\
$\sigma_{\mathrm{O}}\left(\Omega^{-1} \cdot \mathrm{cm}^{-1}\right)$ & $1.3 \times 10^{-3}$ & $3.5 \times 10^{-3}$ & $8.0 \times 10^{-3}$ & $1.5 \times 10^{-2}$ & $3.5 \times 10^{-2}$ \\
$\sigma_{\mathrm{e}}\left(\Omega^{-1} \cdot \mathrm{cm}^{-1}\right)$ & 50 & 42 & 40 & 35 & 30 \\
\hline
\end{tabular}

Table 2 .

Oxygen stoichiometry $(4+\delta)$ and thermodynamic factor $\gamma$ for $\mathrm{La}_{2} \mathrm{Cu}_{0.5} \mathrm{Ni}_{0.5} \mathrm{O}_{4+\delta}$ as a function of temperature and oxygen partial pressure

\begin{tabular}{|c|c|c|c|c|c|c|c|c|c|c|}
\hline \multirow{3}{*}{$\frac{\text { Temperature }\left({ }^{\circ} \mathrm{C}\right)}{\mathrm{P}_{\mathrm{O} 2 \text { (atm) }}}$} & \multicolumn{2}{|c|}{500} & \multicolumn{2}{|c|}{600} & \multicolumn{2}{|c|}{700} & \multicolumn{2}{|c|}{800} & \multicolumn{2}{|c|}{900} \\
\hline & 0.21 & 0.01 & 0.21 & 0.01 & 0.21 & 0.01 & 0.21 & 0.01 & 0.21 & 0.01 \\
\hline & 4.064 & 4.048 & 4.055 & 4.037 & 4.049 & 4.028 & 4.035 & 4.017 & 4.032 & 4.014 \\
\hline$\gamma( \pm 15 \%)$ & \multicolumn{2}{|c|}{385} & \multicolumn{2}{|c|}{342} & \multicolumn{2}{|c|}{292} & \multicolumn{2}{|c|}{340} & \multicolumn{2}{|c|}{340} \\
\hline
\end{tabular}

